\title{
Value of Computed Tomography for Predicting the Outcome After Percutaneous Nephrolithotomy
}

Hassan Shaker ${ }^{1}$, Mohamed Ali Ahmed Ismail ${ }^{2}$, Ahmed M. Kamal ${ }^{2}$, Mohamed Safa ${ }^{1}$, Hisham Refaat ${ }^{2}$, Ahmed Abdelsalam², Mohamed H. Badawy ${ }^{2}$, Hossam Elganzoury ${ }^{2}$, Amr Elkhouly², Samir Ghobashy², Khalid Elesaily², Samoir Eldahshan ${ }^{2}$, Hani H. Nour ${ }^{2}$

${ }^{1}$ Urology Department, Faculty of Medicine, Ain Shams University, Cairo, Egypt

${ }^{2}$ Urology Department, Theodor Bilharz Research Institute, Giza, Egypt

\section{Type of article: Original}

\begin{abstract}
Introduction: Computerized tomography of the urinary tract (CT-UT) has been established as the diagnostic procedure of choice for urinary stones. This study aimed to evaluate its role in predicting the outcome of percutaneous nephrolithotomy (PCNL) in terms of stone free rate and residual fragments.

Method: This prospective cohort study was conducted on 34 patients in the Urology Department of Theodor Bilharz Research Institute from January 2013 to March 2014. The patients who had large and/or multiple renal stones, including staghorn stones, in 19 renal units scheduled for PCNL were included in this study. All had a pre-operative CT-UT to determine the stones' characteristics and renal anatomy. CT-UT, together with a kidneyUreter-Bladder (KUB) film, was taken on the first post-operative day. The data were analyzed by SPSS version 17 using independent-samples t-test and the chi-squared test.

Results: CT-UT showed a statistical significant sensitivity in detecting residual fragments over standard KUB, yet this significance was lost when corrected to significant residual. Stone size and density were independent factors for the presence of residual stones.

Conclusion: CT-UT post PCNL was sensitive to detect residual fragments, yet it showed no superiority over standard KUB in detecting significant residual.

Keywords: Renal stones, CT-UT, PCNL, KUB, residual fragments
\end{abstract}

\section{Introduction}

Percutaneous nephrolithotomy (PCNL) has been established as the treatment of choice for large $(>2 \mathrm{~cm})$ and/or multiple renal stones, including staghorn stones (1); it's less invasive, effective, safe, and with less complications rate in comparison to open renal surgery. The stone-free rate exceeds $95 \%(2)$, and the reported rate of overall complications, including hemorrhage and organ injury, varies from 0.9 to $4.7 \%$ (3). A successful percutaneous nephrolithotomy (PNL) procedure depends upon accurate assessment of the stone burden, location within the collecting system, together with intrarenal anatomy and associated anomalies. For decades, intravenous pyelogram (IVP) was the standard diagnostic procedure for urinary lithiasis (4); it can visualize the size, shape, density, and position of renal stones, and it can evaluate the collecting system inside the kidneys, detect anatomical renal anomalies, and subjectively evaluate renal function. Complications following IVP are rare, and, fortunately, they are mild and self-limited with an overall contrast reaction between 5-8\%, renal insufficiency, mostly reversible, occurs in less than 5\%, and severe respiratory and cardiovascular events are less than 1\% (5). In 1995, Smith et al. (6) introduced helical computerized tomography of the urinary tract (CT-UT) as an alternative to intravenous pyelography, and it has now become the gold standard for diagnosing urinary lithiasis, with a sensitivity and specificity of $95 \%$ and $98 \%$, respectively. A CT-UT scan is fast, does not require iodinated contrast, accurately evaluates stone size, number, density, and renal anatomy, especially with the introduction of multiplanner reconstruction (MPR) and three-dimensional reformatted (3DR) images; it detects other clinically significant

\section{Corresponding author:}

Assistant Professor Dr. Mohamed Ali Ahmed Ismail, Urology Department, Theodor Bilharz Research Institute, Giza, Egypt. Tel: +20.1001494767, E-mail: mazenmera66@gmail.com

Received: September 21, 2015, Accepted: October 28, 2015, Published: November 2015

iThenticate screening: October 22, 2015, English editing: November 05, 2015, Quality control: November 08, 2015 (C) 2015 The Authors. This is an open access article under the terms of the Creative Commons Attribution-NonCommercialNoDerivs License, which permits use and distribution in any medium, provided the original work is properly cited, the use is non-commercial and no modifications or adaptations are made. 
diseases in $13 \%$ of patients with initial diagnosis of urinary calculi (7). When applied to percutaneous renal surgery, CT-UT is used for localization of peripheral stones to anterior or posterior calices, determination of the direction of caliceal extensions of staghorn calculi, evaluation of the thickness of parenchyma overlying calculi, and visualization of low radiodensity stones (8). CT-UT also has been used for evaluating stone free rates, grading postoperative complications, and predicting the outcome of percutaneous renal surgery with superior results over ultrasonography, plain radiography of the kidneys, ureter, and bladder (KUB), and antegrade pyelography (9). The aim of this research was to evaluate the role of unenhanced Spiral CT of the urinary tract in predicting the outcome of PCNL treatment.

\section{Material and Methods}

This was a prospective study, followed the tenets of Helsinki Declaration and was conducted in the Urology Department of Theodor Bilharz Research Institute (TBRI) between January 2012 and March 2013. It included 34 patients with 38 renal units, all of whom had large and/or multiple renal stones, including staghorn stones, and were enlisted to have PCNL as their treatment plan. Pre-operative evaluation included history, clinical examination, and routine laboratory investigation. All patients underwent plain X-ray and CT-UT at $120 \mathrm{kV}$ and $240 \mathrm{~mA}$. The reconstruction interval and the number of images in which the calculus could be visualized varied from 3 to $5 \mathrm{~mm}$. To evaluate the value of CT in predicting the outcome of PCNL, the following factors were correlated to the outcome:

1) Stone side, size, and number

2) Stone density

3) The degree of hydronephrosis according to calyceal configuration

4) Associated renal anomalies

Stone size was determined by measuring the longest diameter, in case of multiple calculi, size was defined as the sum of the longest diameter of each stone. After insertion of the ureteric catheter, PCNL was performed in the prone position, following the puncture of the collecting system and insertion of two guide wires; we routinely dilated the tract using metallic telescopic dilators and then inserted the amplatz sheath. We used a 26F nephroscope and pneumatic energy source for stone fragmentations. Perioperative complications were classified according to the modified Clavien grading system [10]. CT-UT and a standard kidney-ureter-bladder (KUB) film to assess stone clearance were undertaken on the first post-operative day. Clearance was defined as complete disappearance of the renal calculus; fragments of $(<5 \mathrm{~mm})$ were considered as clinically insignificant and were subsequently managed conservatively. Data obtained from the present study were computed using SPSS versions 17 under the platform of Microsoft Windows 7 and using the statistical techniques independent-samples t-test and the chi-squared test. Continuous data were expressed in the form of mean $\pm \mathrm{SD}$, while categorical data were expressed in the form of count and percent. $P$ value less than 0.05 was considered to be statistically significant.

\section{Results}

Basic and clinical characteristics of patients included in this study are presented in Table 1. Using CT-UT, postoperative residual fragments were present in 17 (45\%) out of the 38 renal units included in the study, six (15\%) had residual stones larger than $5 \mathrm{~mm}$ and needed an auxiliary procedure. KUB films failed to detect residual stones in all but four renal units (fragments $>5 \mathrm{~mm}$ ) with significant sensitivity of CT-UT over plain KUB films in detecting residual fragments $(\mathrm{p}<0.05)$, yet this significance was lost when corrected to significant fragments only. The stonefree rate on CT-UT correlated with stone size and density, with no significant difference between presence of residual fragments and stone sie, nor BMI (Table 2). There was a significant decrease of serum hemoglobin postoperatively. Grade I complications according to Clavien grading system occurred in six patients, while two patients had grade III complication. There was no statistical significance in complication rate between stone-free renal units and renal units with residual fragments, and complications didn't correlate between stone size and density. The presence of associated renal anomalies included in the study didn't correlate with the presence of residual fragments on CT-UT $(\mathrm{p}>0.05)$, and the same was found between the degree of hydronephrosis and residual fragments. Evaluating the diagnostic significance of stone density in predicting the presence of residual fragments revealed that at a cut-off $540 \mathrm{HU}$, at this density preoperative CT-UT has sensitivity of $80 \%$, a specificity of $100 \%$, a positive predictive value (PPV) of $100 \%$ and a negative predictive value (NPV) of $83.0 \%$ in predicting residual fragments. Stone size was an indicator for the presence of residual fragments with a cut-off $18 \mathrm{~mm}$ showing $40 \%$ sensitivity, PPV of $30 \%$ in predicting residual fragments. 
Table 1. Perioperative parameters (number of patients: 34 , number of renal units: 38 )

\begin{tabular}{|c|c|c|}
\hline \multirow{3}{*}{$\begin{array}{l}\text { variables } \\
\text { Age }\end{array}$} & \multicolumn{2}{|l|}{ Findings } \\
\hline & Median (range) & $35(22-68)$ \\
\hline & Mean $( \pm$ SD $)$ & $43.2( \pm 13.5)$ \\
\hline Gender (M/F) & \multicolumn{2}{|l|}{$24 / 10$} \\
\hline Stone side (right/left) & \multicolumn{2}{|l|}{$22 / 16$} \\
\hline \multirow[t]{3}{*}{ Stone location } & Pelvis & $20(53 \%)$ \\
\hline & Pelvis+calyceal & $12(30 \%)$ \\
\hline & Staghorn & $6(17 \%)$ \\
\hline \multirow[t]{2}{*}{ Body Mass Index (BMI) } & Median (range) & $26(23-29)$ \\
\hline & Mean $( \pm$ SD $)$ & $30.2( \pm 6.9)$ \\
\hline \multirow[t]{2}{*}{ Stone size $(\mathrm{mm})$} & Median (range) & $76(20-135)$ \\
\hline & Mean $( \pm \mathrm{SD})$ & $51( \pm 45)$ \\
\hline \multirow[t]{2}{*}{ Stone Density(HU) } & Median (range) & $410(280-600)$ \\
\hline & Mean $( \pm$ SD $)$ & $501( \pm 98.7)$ \\
\hline \multirow[t]{3}{*}{ Hydronephrosis } & Mild & $6(17 \%)$ \\
\hline & Moderate & $24(63 \%)$ \\
\hline & Marked & $8(20 \%)$ \\
\hline \multirow{2}{*}{$\begin{array}{l}\text { Associated renal } \\
\text { anomalies }\end{array}$} & Horseshoe kidney & $2(10 \%)$ \\
\hline & Malrotated Kiddney & $1(5 \%)$ \\
\hline
\end{tabular}

Table 2. Relation of treatment outcome to clinical parameters

\begin{tabular}{|l|l|l|l|}
\hline \multicolumn{2}{|l|}{ Variables } & Stone free & Residual Fragments \\
\hline Age & Male & $45.4 \pm 8.5$ & $41.0 \pm 18.1$ \\
\hline \multirow{2}{*}{ Gender } & 14 & 10 \\
\hline FMI & 4 & 6 \\
\hline Pre-operative $\mathrm{Hb}(\mathrm{gm} / \mathrm{dl})$ & $27.0 \pm 2.2$ & $26.3 \pm 1.6$ \\
\hline Post-operative $\mathrm{Hb}(\mathrm{gm} / \mathrm{dl})$ & $13.5 \pm 1.8$ & $12.9 \pm 1.34$ \\
\hline Serum creatinine $(\mathrm{mg} / \mathrm{dl})$ & $12.4 \pm 1.75^{1}$ & $11.6 \pm 1.33$ \\
\hline Stone side & $0.88 \pm 0.1$ & $0.92 \pm 0.1$ \\
\hline \multicolumn{2}{|l|}{ Right } & 12 & 10 \\
\hline Number of stones & 8 & 8 \\
\hline Size of largest stone $(\mathrm{mm})(\mathrm{Mean} \pm \mathrm{SD})$ & $11.8 \pm 0.42$ & $2.0 \pm 0.7$ \\
\hline Total stone size $(\mathrm{mm}),(\mathrm{Mean} \pm \mathrm{SD})$ & $15.7 \pm 0.51$ & $89.8 \pm 5.58^{2}$ \\
\hline Density $(\mathrm{HU})$ & $572.0 \pm 33.46$ & $430.0 \pm 90.76^{4}$ \\
\hline Anomaly & 2 & 1 \\
\hline Complications & 2 & 2 \\
\hline
\end{tabular}

$1: \mathrm{p}<0.05,2: \mathrm{p}=0.049,3: \mathrm{p}=0.022,4: \mathrm{p}=0.011$

\section{Discussion}

Renal stone management depends upon several factors, including stone burden, density, renal anatomy, and associated anomalies (2). Currently CT-UT has replaced the classic IVP in evaluating patients with urinary stones (8); post-operative CT-UT also is used very liberally by urologists in the followup, yet still in our country, CT-UT is expensive and not available in every medical facility. Evaluating residual stones via fluoroscopy is largely dependent on stone opacity and size. It has been reported that the Hounsfield unit (HU) values determined in the unenhanced CT is associated with the visibility of stones on plain radiography (11). In our study, we tried to evaluate the use of CT-UT in predicting the outcome in terms of stone-free rate and presence of residual fragments after PCNL. CT-UT was able to detect residual fragments in $45 \%$ of the cases (18 renal units), which was extremely high in relation to standard KUB films, which detected residual stones in only four renal units. This detection rate was corrected to only $15 \%$ (six renal units) when we considered only detection of significant fragments (>5 mm). This was in accordance to what was found by Park et al. (9), who reported a stone-free rate of $20 \%$ on post PCNL CT-UT, which increased to $41 \%$ when considering only significant residual. In our study, CT-UT failed to prove a significant advantage over KUB in detecting significant residual stones. Regarding the predictors of treatment 
outcome in the present study, it was found that stone-free renal units had lower stone burden and higher HU density than renal units with residual fragments. This is in agreement with Gucuk et al. (12), who found that HU value and stone size are significant predictors for stone-free rates after PCNL. This study has several limitations. It had a small sample size, only three patients with two renal anomalies were included, and it didn't take into consideration the technical experience of the surgeon.

\section{Conclusions}

Stone size and density calculated by CT-UT can predict the presence of residual fragments after PCNL. Postoperative CT-UT is associated with over detection of insignificant fragments with no added benefit over standard KUB films in detecting significant residual. Taking into consideration the cost and availability of CT-UT in our country, we think that its use post PCNL has to be reserved for selected cases, depending on the post-operative course.

\section{Acknowledgments:}

The authors thank the Theodor Bilharz Research Institute for supporting this study.

\section{Conflict of Interest:}

There is no conflict of interest to be declared.

\section{Authors' contributions:}

All authors contributed to this project and article equally. All authors read and approved the final manuscript.

\section{References}

1) Perminger GM, Assimos DG, Lingeman JE, Nakada SY, Stuart Wolf J, Pearle M. AUA guideline on management of stag horn calculi: diagnosis and treatment recommendations. J Urol. 2005; 173: 1991-2000. doi: 10.1097/01.ju.0000161171.67806.2a

2) Dayal, A, Selvaraju K, Prabhu G. Prospective study of Percutaneous Nephrolithotripsy as monotherapy in treatment of renal calculi. Internet Journal of Urology. 2008; 5(2): 5.

3) Michel MS, Trojan L, Rassweiler JJ. Complications in percutaneous nephrolithotomy. Eur Urol. 2007; 51: 899-906. doi: 10.1016/j.eururo.2006.10.020, PMID: 17095141

4) Sandhu C, Anson KM, Patel U. Urinary tract stones--Part I: role of radiological imaging in diagnosis and treatment planning. Clin Radiol.2003; 58: 415-21. doi: 10.1016/S0009-9260(03)00103-X.

5) Renard-Penna R, Marcy PY, Lacout A, Thariat J. Imaging of the kidney. Bull Cancer 2012; 99(3): 251-62, PMID: 22157576

6) Smith RC, Rosenfield AT, Choe KA, Essenmacher KR, Verga M, Glickman MG, et al. Acute flank pain: comparison of unenhanced-enhanced CT and intravenous urography. Radiology. 1995; 194(3): 789-94. doi: 10.1148/radiology.194.3.7862980, PMID: 7862980

7) Silverman SG1, Leyendecker JR, Amis ES Jr. What Is the Current Role of CT Urography and MR Urography in the Evaluation of the Urinary Tract? Radiology. 2009; 250: 393-423. doi: 10.1148/radiol.2502080534,, PMID: 19188307

8) Park S, Pearle MS. Imaging for percutaneous renal access and management of renal calculi. Urol Clin North Am. 2006; 33:353-364. doi: 10.1016/j.ucl.2006.03.003, PMID: 16829270.

9) Park J, Hong B, Park T, Park HK. Effectiveness of noncontrast computed tomography in evaluation of residual stones after percutaneous nephrolithotomy. J Endourol. 2007; 21: 684-687. doi: 10.1089/end.2006.0352, PMID: 17705749.

10) Tefekli A1, Ali Karadag M, Tepeler K, Sari E, Berberoglu Y, Baykal M. Classification of percuta- neous nephrolithotomy complications using the modified Clavien grading system: looking for a standard. Eur Urol. 2008; 53: 184-90. doi: 10.1016/j.eururo.2007.06.049, PMID: 17651892

11) Huang $\mathrm{CC} 1$, Chuang $\mathrm{CK}$, Wong YC, Wang LJ, Wu CH. Useful prediction of ureteral calculi visibility on abdominal radiographs based on calculi characteristics on unenhanced helical CT and CT scout radiographs. Int. J. Clin Pract. 2009; 63: 292-8. doi: 10.1111/j.1742-1241.2008.01861.x, PMID: 19196367.

12) Gücük A, Uyetürk U, Oztürk U, Kemahli E, Yildiz M, Metin A. Does the Hounsfield unit value determined by computed tomography predict the outcome of percutaneous nephrolithotomy? J Endourol. 2012; 26(7): 792-6. doi: 10.1089/end.2011.0518, PMID: 22201298 